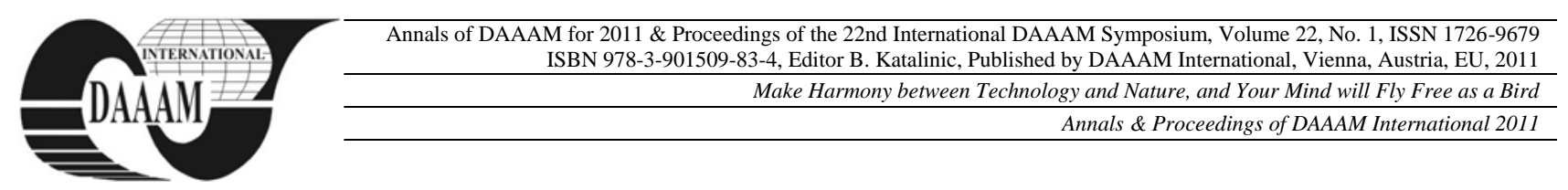

\title{
PHYSICAL PROPERTIES OF FILLED EPOXY COMPOSITES
}

\author{
CIRCIUMARU, A[drian]; BRIA, V[asile]; ROMAN, I[gor]; ANDREI, G[abriel]; \\ DIMA, D[umitru] \& BIRSAN, I[ulian] G[abriel]
}

\begin{abstract}
It is well known that the quality of a composite depends not only in its components quality but also in forming technology. Regarding particulate polymer composites the mentioned dependence is stronger. This study is about how the filler's dispersion into the matrix is influencing the basic properties of filled composites. In the case of moulded thermosetting based composites three ways to disperse the powders into the matrix are available leading, probably, to different final properties. In this study the epoxy system EPIPHEN RE 4020 - DE 4020 was used as matrix and Starch, Clay, Talc, CNT, Aluminium titanate, Lithium titanate as fillers. Key words: epoxy, clay, talc, starch, aluminum titanate, lithium titanate
\end{abstract}

\section{INTRODUCTION}

By definition, fillers are used to extend a material and to reduce its cost. However, few inexpensive types of fillers, such as walnut shells, fly ash, wood flour, and wood cellulose, are still being used purely for filling purposes; nearly all fillers employed provide more than space filling. Considering their relative higher stiffness compared to the material matrix, they will always modify the mechanical properties of the final filled products, or composites. Fillers and additives may modify or impart electromagnetic properties, such as electrical conductivity of the final material (Tsou \& Wadell, 2004). Conductive fillers are used to provide the polymer with electrical conductivity. The simplest fillers are metal particles such as gold, silver, nickel, indium, copper, chromium, etc.

Isotropic conductive polymers, also called as polymer solder, are composites of polymer resin and conductive fillers. The conductive fillers provide the composite with electrical conductivity through contact between the conductive particles. With increasing filler concentrations, the electrical properties of such polymer transform from an insulator to a conductor. Percolation theory has been used to explain the electrical properties of filled polymer composites. At low filler concentrations, the resistivity of particulate composites decreases gradually with increasing filler concentration.

As a general rule the polymer composites, as well as ceramic or metal matrix composites, are imparted in particulate (filled) and reinforced or combinations of them. In each case the composite material is formed to solve a problem, to maximize a property for a certain application (Gay et al, 2003; Daniel \& Ishai, 2006; Jones, 1998; Vasiliev \& Morozov, 2001). Carbon fiber reinforced polymers, for instance, are used and formed for low weight and high strength especially for motor sports but in this case it might be done more due to the electrical properties of carbon fiber; namely it might be possible to achieve information about structure's state via electrical resistivity of carbon fibers (or tows).

This study is just a part of a larger one regarding complex polymer composites reinforced with fibers fabrics and with particulate matrix meant to reach more capabilities for final material. The use of fabrics ensures the fibers spatial distribution and use of fillers solves physical properties. In this case it has to be known the way each filler reacts with the polymer aside the necessity of ensure the interface between fibers and polymer. Due an appropriate forming technique (layer-by-layer, for instance) it is possible to obtain laminated-like materials having other fabric in each reinforcement layer and other filler in each polymer layer but keeping the same polymer bonds into material's volume.

\section{MATERIALS}

The Epoxy system RE 4020 - DE 4020 was used as matrix to form particulate composites with Clay, Talc, Starch, CNT, Aluminum titanate and Lithium titanate. Each of the fillers is used on a certain purpose connected to the final properties of the composite.

The use o Clay is recommended by its capacity to generate nanostructures inside the matrix each nano-plate of clay acting as a crystallization germ and changing, locally, the normal polymer structure with effects on mechanical properties of the final material due to the soft loading transfer between the crystalline and amorphous phases (Winey \& Vaia, 2007). The clay powder used to form the particulate composites is one of cosmetic application so it contains organic substance aside the mineral one.

The presence of the Talc inside a polymer matrix increases the fire resistance and contributes to better mechanical properties. The presence both of Clay and Talc leads to a material which act as a liquid with very high viscosity because the ordered zones surrounding the Clay or Talc particles are connected through typically polymer bonds. It is expected that the particulate composite to show lower mechanical properties but higher dimensional stability.

Starch is known as a good dispersant and also is known for its capability to form structures inside liquid phases. Starch also may be easily functionalized with various ions and it might be used to transport transitional metals' ions, via complex combinations, inside the polymer structure solving in reasonable limits the problem of electrical conductivity (and not only).

The use of CNT is intended for changing electric behavior. As per Aluminum titanate and Lithium titanate, they are used due their capacity to form nano-structures inside the polymer matrix. Taken separately each of the fillers may be used to obtain a benefit but the problem is to use all of them to fill the same matrix. This type of filled polymer might be also used as matrix for a reinforced composite (with long fibers or fabrics) such as, at least, one design problem to be solved in one layer of the hybrid composite. Using various polymers in various layers it is more possible to control the design of composite materials or composite structures.

For each of above mentioned fillers three types of materials were formed with a volume ratio of $2 \%$ filler/polymer. The first type (denoted as A) consists in mechanical dispersion of fillers' particles into the liquid component A of epoxy system (bisphenol A) followed by adding of right amount of B component (aliphatic amine complex). The second type (denoted as B) consists in mechanical dispersion of filler into the liquid component $\mathrm{B}$ of the epoxy system while the third type (denoted as $\mathrm{P}$ ) consists in dispersion of filler into the pre- 
polymer mixture of right amounts of $\mathrm{A}$ and $\mathrm{B}$ components of epoxy system.

\section{MEASUREMENTS AND RESULTS}

The specific weight of formed composites was taken into account. The mixing rule is giving the same result for all three types of materials (A, B or P) and it is not taking into account the interactions. In Table 1. there are presented specific weight values for powders, epoxy and particulate composites, as well as the theoretical value as it results through application of mixing rule (Torquato, 2000; Callister, 2007; Withers, 2007).

\begin{tabular}{|c|c|c|c|c|c|}
\hline & Powder & $\begin{array}{c}\text { Theoretical } \\
\text { mixing rule }\end{array}$ & $\begin{array}{c}\mathrm{A} \\
\text { type }\end{array}$ & $\begin{array}{c}\mathrm{B} \\
\text { type }\end{array}$ & $\begin{array}{c}\mathrm{P} \\
\text { type }\end{array}$ \\
\hline Epoxy & 1.128 & & & & \\
\hline Starch & 0.588 & 1.118 & 1.090 & 1.165 & 1.240 \\
\hline Talc & 0.763 & 1.121 & 1.113 & 1.160 & 1.087 \\
\hline Clay & 0.608 & 1.118 & 1.145 & 1.212 & 1.125 \\
\hline $\begin{array}{c}\text { Lithium } \\
\text { titanate }\end{array}$ & 1.210 & 1.130 & 1.180 & 1.208 & 1.132 \\
\hline $\begin{array}{c}\text { Aluminum } \\
\text { titanate }\end{array}$ & 1.913 & 1.144 & 1.231 & 1.180 & 1.068 \\
\hline CNT & 0.047 & 1.107 & 1.146 & 1.163 & 1.125 \\
\hline
\end{tabular}

Tab. 1. Specific weight of components and materials

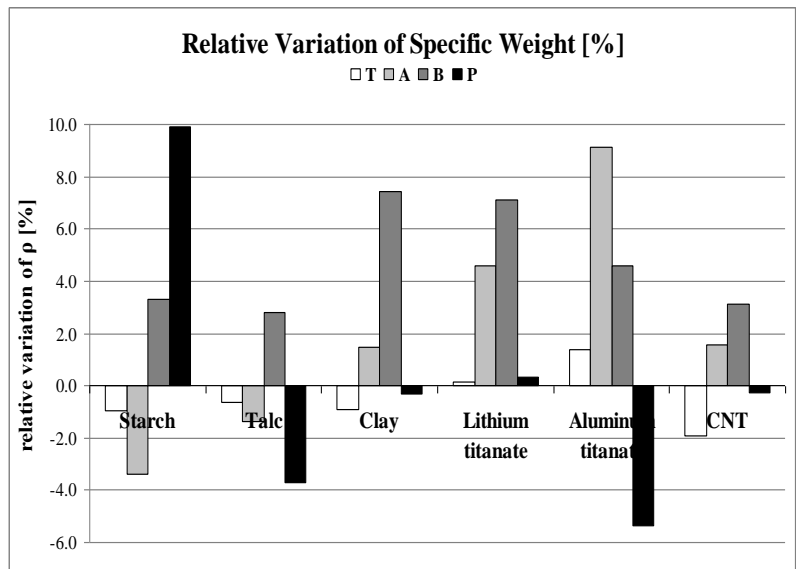

Fig. 1. Relative variation of specific weight

It might be noticed that excepting the case of the two titanate compounds al the theoretical relative variations are negative due to the low value of powder density but for formed materials the situation differs. In the case of CNT it is known that they absorb large quantities of liquids fact which explains the higher values of density for A and B types of materials (the two components are absorbed during the initial dispersion) while in the case of P-type material the CNT are dispersed into a more viscose liquid and the absorption process is limited and leads to a value comparable with the one of epoxy. The situation is the same in the case of clay filled epoxy with the observation that both in case, as well as in the case of lithium titanate the B-type materials show higher values for specific weight denoting a strong interaction between particles and B component of epoxy system leading to a superior packaging of polymer chains.

Generally it might be said that the presence of fillers' particles leads to two different tendencies one consists in decreasing of density while the other one consists in increasing the density. First one is denoting a poor volume density of polymer chains while the other one is denoting a high volume density of polymer chains - as in the most significant cases of P-Starch and A-Aluminum titanate. In this two situations is like inside the polymer some heavier structures are formed while, as opposite pole, the cases of A-Starch,
P-Aluminum titanate, P-Clay when is like the presence of fillers' particles are increasing the distances between polymer chains. The P-Lithium titanate is the single case in which the measured value is comparable with calculated one meaning that the mixing rule may be applied and therefore there is not interaction between particles and polymer molecules.

\section{CONCLUSIONS}

As it was mentioned ay the beginning the aim of this study is to identify the way in which the forming technique is influencing the final properties of the particulate composites but above analysis is not enough to offer explanations for all the changes. A microscopic analysis has to be performed in order to point out the structural changes. The presented analysis is just a qualitative one.

In the case of use of such filled polymers as matrix to form reinforced composites it is necessary to know the way in which the forming technique (the dispersion) is influencing the final properties. Mechanical and tribological analysis has to be performed to offer accurate information about the presented filled polymers. Even the basic constituents are the same it is easy to notice that is possible to set various densities in various ways leading to the possibility to form a reinforced material based in the same polymer and same filler but having various behaviour in various matrix or reinforcement layers.

Even the design problem is a complex one the presented results are encouraging further studies regarding filled polymers and reinforced materials with filled polymer matrix to achieve more advantages forming a material. Another aspect is connected with the description of particulate composite's properties in terms of powder and polymer properties. It is possible to guess the properties of a filled but it is necessary to measure them to make right decisions. For this type of materials a chemical analysis (crystallization degree, molar mass etc) has to be carried out because it is expected that lowering the fillers' particles dimensions to assist at a chemical (if not even quantum) interaction between polymer molecules and fillers' molecules.

\section{REFERENCES}

Callister, W. D. Jr. (2007), Materials Science and Engineering, 7th ed., John Wiley \& Sons, ISBN-10:0-471-73696-1

Daniel, I \& Ishai, O. (2006), Engineering Mechanics of Composite Materials, Oxford University Press, New York, USA, ISBN: 019515097X

Gay, D., Hoa, S. V., Tsai, S. W. (2003) Composite Materials Design and Applications, CRC Press, Boca Raton, USA, ISBN: 58716-084-6

Jones, R.M. (1998) Mechanics of Composite Materials, Taylor\&Francis Inc., Philadelphia, USA, ISBN: 1-56032$712-\mathrm{X}$

Torquato, S. (2000) Modeling of physical properties of composite materials, International Journal of Solids and Structures, 37, pp. 411-422, ISSN 0020-7683

Tsou, A.H., Waddell, W.H. (2004), Fillers, in Mark, H.F. (ed), Encyclopedia of Polymer Science and Technology, John Wiley \& Sons, Inc., vol. 10, pp. 1 - 20, ISBN: 978-0-47127507-7

Vasiliev, V. V., Morozov, E. V. (2001) Mechanics and Analysis of Composite Materials, Elsevier, ISBN: 0-08-042702-2

Winey, Karen, I. and Vaia, R. A., (2007). Polymer Nanocomposites. MRS Bulletin, 32, pp 314-322 doi:10.1557/mrs2007.229, ISSN 0883-7694

Withers, P. J. (2007), Composites, Physical Properties of, in Mortensen, A., Concise Encyclopedia of Composite Materials, Elsevier, pp. 215 - 224, ISBN-13: 978-0-08-045126-8 